\title{
CHARACTERISTICS OF CARBON PYROLYZED FROM TABLE SUGAR AND SUCROSE FOR Pt-LESS DSSC COUNTER ELECTRODE
}

\author{
Nofrijon Sofyan ${ }^{1,2 *}$, Muhammad $^{1}$, Aga Ridhova ${ }^{1}$, Akhmad Herman Yuwono $^{1,2}$, \\ Arief Udhiarto ${ }^{3}$ \\ ${ }^{1}$ Department of Metallurgical and Materials Engineering, Faculty of Engineering, Universitas \\ Indonesia, Kampus UI Depok, Depok 16424, Indonesia \\ ${ }^{2}$ Tropical renewable Energy Center, Faculty of Engineering, Universitas Indonesia, Kampus UI Depok, \\ Depok 16424, Indonesia \\ ${ }^{3}$ Department of Electrical Engineering, Faculty of Engineering, Universitas Indonesia, Kampus UI \\ Depok, Depok 16424, Indonesia
}

(Received: December 2017 / Revised: December 2017 / Accepted: February 2018)

\begin{abstract}
Platinum is the most effective counter electrode for use in dye-sensitized solar cells (DSSC). However, as platinum is very expensive, its price impedes its broad use as a DSSC counter electrode. As an alternative, carbon has been used for this purpose. In this study, carbon has been successfully pyrolyzed from the precursors of table sugar and sucrose through a chemical process, i.e. the dehydration of the precursors with sulfate acid followed by a pyrolysis process, and used as Pt-less counter electrode in a DSSC device. The as-synthesized carbon was characterized using X-ray diffraction (XRD) to obtain crystal structure information and a scanning electron microscope (SEM) equipped with energy dispersive X-ray spectroscopy (EDX) was employed to carry out morphological and compositional examination. The material activity and performance of the counter electrode in the DSSC device were analyzed using a semiconductor parameter analyzer through current-voltage characteristic curves (I-V). The results show that the precursors of table sugar without the addition of a metal catalyst and with initial heat treatment at $300^{\circ} \mathrm{C}$ for 1 hour, and of sucrose with a catalyst could produce carbon with a particle size of around 600 $900 \mathrm{~nm}$. The I-V curve characteristic of the DSSC device assembled using carbon produced from sucrose as a counter electrode resulted in a power conversion efficiency (PCE) of only $0.041 \%$, whereas the DSSC device assembled using carbon produced from table sugar as a counter electrode exhibited a good performance with a PCE of $3.239 \%$, almost equivalent to that of platinum paste with a PCE of $4.024 \%$. This result is promising in terms of using a cheap source of carbon for the Pt-less counter electrode.
\end{abstract}

Keywords: Dye-sensitized solar cell; Power conversion efficiency; Pt-less counter electrode; Sucrose; Table sugar

\section{INTRODUCTION}

In the midst of today's ever-increasing energy demands, the oil and gas sector can no longer be expected to serve as a primary source in supplying these demands. The main reason for this, in addition to its decreasing availability, is that the resulting emissions of these fossil-based fuels are not environmentally friendly. Hence, an alternative energy source is required to overcome this problem and to compensate for the shortage of oil and gas resources. One of the possible

\footnotetext{
*Corresponding author's email: nofrijon.sofyan@ui.ac.id, Tel. +62-21-7863510, Fax.+62-21-7872350 Permalink/DOI: https://dx.doi.org/10.14716/ijtech.v9i2.988
} 
alternatives, especially for tropical countries constantly exposed to sunlight, is to harness the abundant energy resource provided by sunlight through the use of solar cell devices. One type of solar cells that may be used are dye-sensitized solar cells (DSSC).

A DSSC is a third-generation solar cell first introduced by O'Regan and Grätzel (1991). The working principle of this DSSC is based on the photo-electrochemical principle in which the electrons of the dye will be excited after being exposed to light such that the dye will be in an oxidized state. The electrons will be injected into a semiconductor conduction band that acts as a photoanode. The electron charge on this photoanode is transferred to the opposite electrode, which is known as the counter electrode. This counter electrode will collect electrons and catalyze the reduction of electrolyte, which is usually in the forms of triiodide into iodide, enabling the reaction result to regenerate the lost electrons from the dye (Chen \& Shao, 2016). In this instance, the counter electrode is one of the components that has an important role in the performance of the DSSC.

In order for a material to be used as a counter electrode, it must have high conductivity, good electro-catalytic properties, and good chemical stability (Wang et al., 2014). Due to its inherent properties, platinum $(\mathrm{Pt})$ would be the best option for a DSSC counter electrode. However, the high price of platinum impedes its broad use in DSSC devices. For this reason, various other materials have been studied with the aim of producing a Pt-less counter electrode. Among these substitute materials are a conductive polymer with a power conversion efficiency (PCE) value of 7.15\% (Li et al., 2008b), a composite material with a PCE value of 5.69\% (Al-Bahrani et al., 2015), and a metal oxide with a PCE value of $8.48 \%$ (Du et al., 2017).

Carbon and its allotropic variety has also been extensively investigated as a cheap platinum-less counter electrode. This is because carbon material, in addition to involving relatively cheaper production costs and being more abundant, also meets the three requirements of the DSSC counter electrode, i.e. high conductivity, good electro-catalytic properties, and good chemical stability (Wang et al., 2014). Among the various carbon allotropes, carbon black has the most accessible structure, and the cost of its fabrication is also relatively lower than that of other structural fabrications. Research has found that a carbon black counter electrode could achieve a PCE of $8.29 \%$, close to the value produced by a DSSC with a platinum counter electrode: a PCE of $8.35 \%$ (Wu et al., 2016). The use of carbon black, however, should be avoided due to its possible carcinogenic effect on humans (Ramanakumar et al., 2008).

In this study, the properties of carbon pyrolyzed from the low-cost resources of table sugar and sucrose have been examined. Furthermore, the electro-catalytic characteristics of the carbon used as a Pt-less counter electrode in a DSSC device were investigated and the results are presented and discussed in detail.

\section{METHODS}

\subsection{Materials}

The materials used were titanium dioxide nanoparticle $\left(\mathrm{TiO}_{2} \mathrm{P}-25\right.$ Degussa, $\left.\phi<80 \mathrm{~nm}\right)$, ethanol (99\%, Merck), table sugar (Gulaku, obtained from a market in Jakarta, $\phi>10 \mu \mathrm{m})$, sucrose (99\%, Merck, $\phi>10 \mu \mathrm{m}), \mathrm{FeSO}_{4} .7 \mathrm{H}_{2} \mathrm{O}$ (99\%, Merck), sulfuric acid (98\%, Merck), platinum-based paste (Platisol, Solaronix), liquid electrolyte (Iodolite, Solaronix), commercial sensitizer (RK-1, Solaronix), Polyvinylidene fluoride (PVDF, MTI), and N-methyl-2-pyrolidone (NMP, MTI).

\subsection{Carbon Pyrolysis}

The pyrolysis of carbon was begun by firstly crushing $5 \mathrm{~g}$ of carbon precursors (sugar or sucrose) using a mortar and pestle. The precursor was numbered in accordance with its treatment, as shown in Table 1. Samples with the addition of a catalyst were mixed and ground with a mortar and 
pestle to a uniform fine powder. In the case of the preheated sample, the sample was heated on a hot plate for 1 hour before being ground in a ball mill to obtain a fine powder. Each sample was then added to $5 \mathrm{ml}$ of $98 \% \mathrm{H}_{2} \mathrm{SO}_{4}$ to produce a carbon aggregate based on the following reaction equation:

$$
\mathrm{C}_{12} \mathrm{H}_{22} \mathrm{O}_{11}(\mathrm{~s})+\mathrm{H}_{2} \mathrm{SO}_{4}(\mathrm{l}) \rightarrow 12 \mathrm{C}(\mathrm{s})+12 \mathrm{H}_{2} \mathrm{O}(\mathrm{g})+\mathrm{SO}_{3}{ }^{-}(\mathrm{g})
$$

Due to the exothermic reaction, some of the water content produced evaporated. The resulting carbon was then transferred into a tube furnace and was heated up to a temperature of $1330^{\circ} \mathrm{C}$ for 4 hours under an argon gas atmosphere. Lastly, the carbon resulting from this process was characterized and the samples having particles close to nanosize were used to fabricate the DSSC device.

Table 1 List of precursors and specific treatments

\begin{tabular}{clcc}
\hline Sample & Precursor & Catalyst & Preheating \\
\hline 1 & Table Sugar & $\mathrm{FeSO}_{4} .7 \mathrm{H}_{2} \mathrm{O} 25 \mathrm{mg}$ & - \\
2 & Table Sugar & - & - \\
3 & Table Sugar & - & $300^{\circ} \mathrm{C}$ \\
4 & Sucrose & $\mathrm{FeSO}_{4} .7 \mathrm{H}_{2} \mathrm{O} 25 \mathrm{mg}$ & - \\
5 & Sucrose & - & - \\
\hline
\end{tabular}

Each of the as-synthesized carbon samples was characterized using X-ray diffraction (XRD, ARL OPTX-2050) to confirm the phase formed and its crystallite size. Attenuated reflectance Fourier transform infrared spectroscopy (FTIR, Perkin Elmer, ATR Spectrum 2) was used to identify and confirm the presence of a functional group. A scanning electron microscope (SEM, FEI Quanta 450) was used to examine the morphology and determine the average particle size of the samples.

\subsection{DSSC Fabrication}

A powder composed of $\mathrm{TiO}_{2}$ nanoparticles was dissolved in $98 \%$ ethanol, with a mass to volume ratio of 1:10, to form a paste. The paste was deposited using the doctor blade method on a conductive surface of a fluorine doped tin oxide (FTO) glass substrate, with masking tape at the edges acting as a thickness regulator and forming an area of $1 \times 1 \mathrm{~cm}^{2}$. The glass substrate was then heated over a hot plate at a temperature of $450^{\circ} \mathrm{C}$ for 45 minutes to remove the solvent. After the heating, the glass substrate was allowed to cool down to room temperature and was subsequently stained using RK-1 dye and sterilized overnight.

The counter electrode was prepared using the as-synthesized carbon. A total $0.15 \mathrm{~g}$ of PVDF and $0.15 \mathrm{~g}$ of carbon were dissolved in $1 \mathrm{~g}$ of NMP to form a paste. This paste was deposited onto the FTO glass by the same method as was used for the $\mathrm{TiO}_{2}$ nanoparticles, and it was then heated at a temperature of $450^{\circ} \mathrm{C}$ for 20 minutes. As a comparison, a Pt-based counter electrode was also prepared using a platinum-based paste which was deposited onto an FTO glass substrate and was heated at $450^{\circ} \mathrm{C}$ for 30 minutes.

The DSSC device was then prepared by attaching the $\mathrm{TiO}_{2}$ conductive glass and counter electrodes to one another using double tape, which also served to prevent direct contact between the photoanode and counter electrode. The device was clamped using binder clips at both ends and the electrolyte was injected in the gap between the photoanode and counter electrode. The characteristics and cell activity of the fabricated DSSC were tested using a semiconductor parameter analyzer (SPA, Agilent 4145A) with a standard illumination of approximately $100 \mathrm{~mW} / \mathrm{cm}^{2}$. 


\section{RESULTS AND DISCUSSION}

Figure 1 shows an X-ray diffractogram of each sample: (a) Sample 1; (b) Sample 2; (c) Sample 3; (d) Sample 4; and (e) Sample 5. As demonstrated in Figure 1, all of the diffractograms show the same trend with two broad peaks at $25^{\circ}$ and $43^{\circ}$, corresponding to the crystalline reflections from (002) and (101) planes. This result is in agreement with those found by other researchers (Zhu et al., 2015; Kumar et al., 2017).

The crystallite size of each sample was calculated using the Scherrer formula (Cullity, 1978):

$$
c_{s}=\frac{k \lambda}{B \cos \theta}
$$

where $c_{\mathrm{s}}$ is the crystallite size, $\lambda$ is the wavelength of the $\mathrm{X}$-ray radiation $(\mathrm{Cu} \mathrm{K \alpha}=0.15406 \mathrm{~nm})$, $k$ is a constant taken as $0.94, \theta$ is the diffraction angle, and $B$ is the full width at half maximum peak in radians. Details of the results are given in Table 2. As seen in Table 2, Sample 2, which uses table sugar without the addition of a catalyst, has the smallest average crystallite size of all the samples, while the largest crystallite size is exhibited by Sample 4, which is the sucrose sample with the addition of a catalyst. If the five samples are grouped according to the use of metal catalysts, it can be concluded that the addition of metal catalysts to the sample affects the crystallite size, and the metal catalyst remains in the post-pyrolysis synthesis sample. On the contrary, the samples with no catalyst addition are dominated by carbon with low crystallinity values.

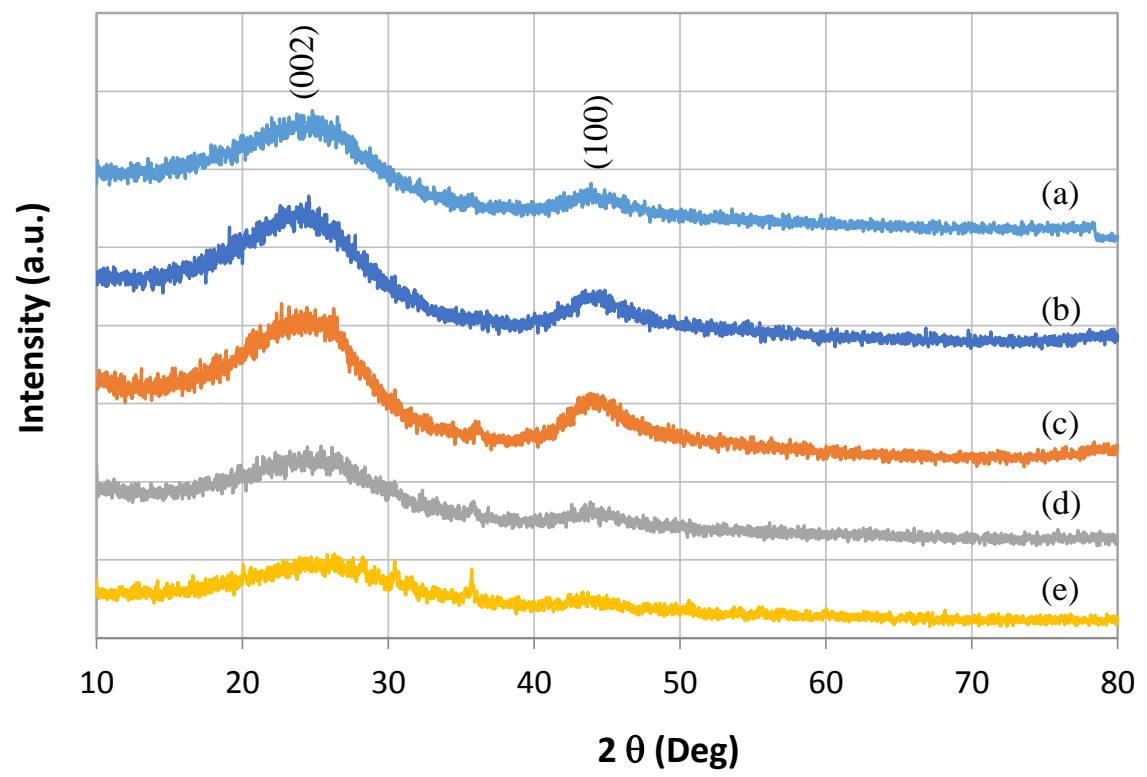

Figure 1 X-ray diffractograms of: (a) Sample 1; (b) Sample 2; (c) Sample 3; (d) Sample 4; and (e) Sample 5

Table 2 Comparison of the average crystallite size

\begin{tabular}{cc}
\hline Sample & Average crystallite size $(\mathrm{nm})$ \\
\hline 1 & 47.79 \\
2 & 17.84 \\
3 & 36.05 \\
4 & 53.68 \\
5 & 19.66 \\
\hline
\end{tabular}


Infrared measurement was performed in order to examine the presence of a functional group in the samples. Figure 2 shows the infrared spectra of the carbon samples and the identified functional group with weak absorption peaks seen at $1083 \mathrm{~cm}^{-1}(\mathrm{C}-\mathrm{C}, \mathrm{C}-\mathrm{O}), 2158 \mathrm{~cm}^{-1}(\mathrm{C} \equiv$ $\mathrm{C})$, and $3236 \mathrm{~cm}^{-1}(\mathrm{C}-\mathrm{H}, \mathrm{O}-\mathrm{H})$. These results are in line with the findings reported by other researchers with regard to the FTIR result of carbon black (Zappielo et al., 2016). These results suggest that only a small number of functional groups are present in the sample and that the pyrolysis of the precursors to carbon has been successfully carried out.

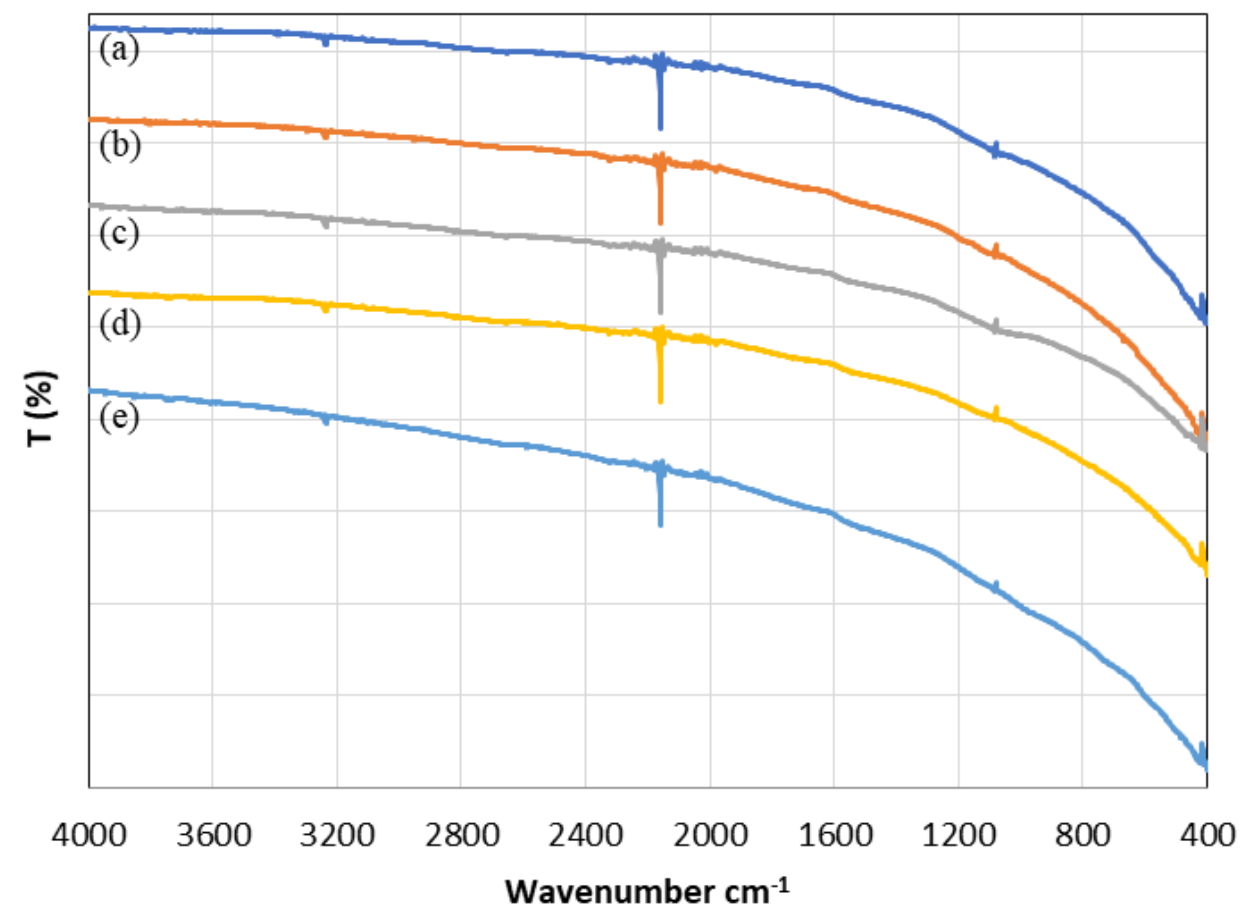

Figure 2 Infrared spectra of: (a) Sample 1; (b) Sample 2; (c) Sample 3; (d) Sample 4; and (e) Sample 5

A scanning electron microscope (SEM) was used to examine the morphology of the samples and the results are provided in Figure 3. Figures $3 \mathrm{a}$ and $3 \mathrm{~b}$ show the morphology of particles having flakes, with particle sizes greater than 1 micron. The white spots in the samples, in according to EDX results, are iron left by the catalyst. Both of these samples bear similarity to results found by other researchers (Chen \& Shao, 2016). Furthermore, neither of these samples were considered for the next stage of testing as they did not fulfil the criteria of having particles close to nanosize, as defined earlier. As for Figure 3c, this sample exhibits a morphology of relatively small particle size with a spherical shape of about $600-630 \mathrm{~nm}$, whereas Figure $3 \mathrm{~d}$ shows an average particle size of up to $900 \mathrm{~nm}$. Accordingly, both Samples 3 and 4 were used for the DSSC device fabrication. As for Sample 5, no good representation of the secondary electron image was obtained: the sample had a very large particle size, so it was excluded from further examination.

Nanoparticles should have better electro-catalytic properties than those of graphite because the most active site in which the catalytic process is conducted on the carbon material would be at the edges ( $\mathrm{Li}$ et al., 2008a). Thus, the smaller the size of the particles of carbon, the greater its catalytic activity and the better its conductivity (Chen \& Shao, 2016). Another reason why both sucrose and table sugar can turn into fine-sized particles is due to the purpose of the pyrolysis process itself, which is to decompose the chemical structure of organic matter through a heating process with little or no oxygen to gas phase. However, since the pyrolysis temperature was relatively high, carbonization took place. In this case, the table sugar and sucrose decomposed, leaving carbon as a residue. With regard to Samples 1 and 2, which used sugar precursors, it 
seems that the sugars did not form small particles during the heating process because of an incomplete decomposition process. In Sample 3, the small particle size is presumed to have been caused by the preheating treatment. The organic molecules in the sugar decompose due to the combustion during the preheating treatment of $300^{\circ} \mathrm{C}$ for 1 hour. In this instance, there would be a change from $\mathrm{C}_{12} \mathrm{H}_{22} \mathrm{O}_{11}$ to carbon and water vapor. At this early stage of heating, carbonization has also begun to occur and the size of the carbon particles is reducing. Thus, when the pyrolysis stage took place, the carbonization continued to occur during the next stage of the process, causing the size of the previously formed carbon particles to reduce even further.
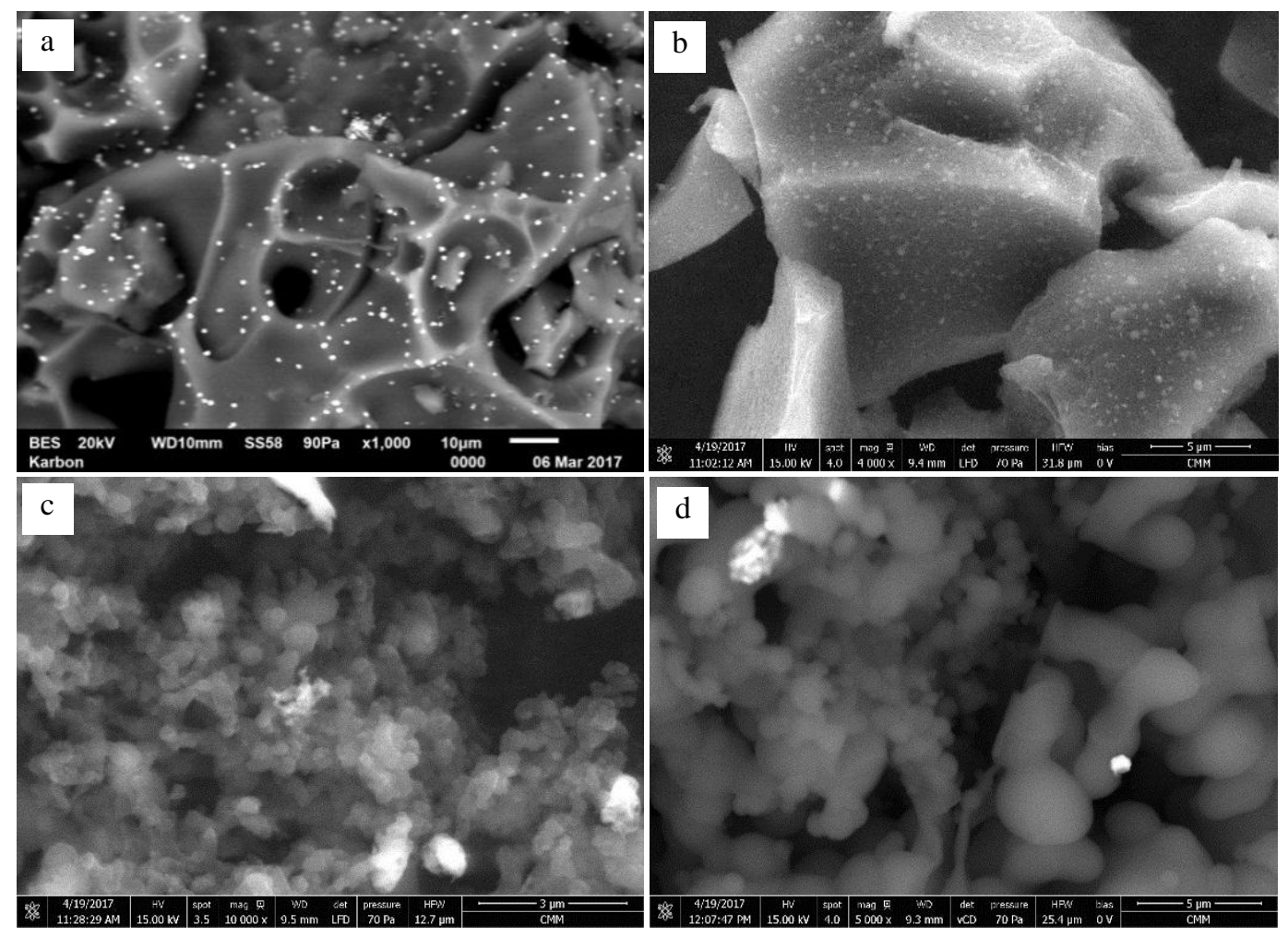

Figure 3 Secondary electron images of sample morphology: (a) Sample 1; (b) Sample 2;

(c) Sample 3; and (d) Sample 4

As has been mentioned previously, based on the SEM results, the samples having particles close to nanosize were further considered in the fabrication of a DSSC device, in this instance, Samples 3 and 4 . The properties of the carbon pyrolyzed from both table sugar and sucrose in the DSSC device were examined through an I-V curve characteristic and the results are given in Figure 4. As seen in Figure 4, the current-voltage curve characteristic of the DSSC device that uses carbon from Sample 3 exhibits a current density much larger than that of Sample 4. Details of the data are presented in Table 3. As a comparison, the results of a DSSC device using platinum paste as a counter electrode (Sofyan et al., 2017) are also presented in this table.

This finding is in agreement with the research of others which demonstrated that reducing the dimensions of carbon black will cause an increase in its electro-catalytic properties, leading to an increase in the PCE value of the DSSC (Chen \& Shao, 2016). In terms of efficiency, this current result $(3.239 \%)$ is still lower than that of the DSSC that uses platinum as a counter electrode $(4.024 \%)$. However, in terms of production costs, a DSSC with this form of carbon would be one of the candidates worthy of consideration as a cheap Pt-less counter electrode. 


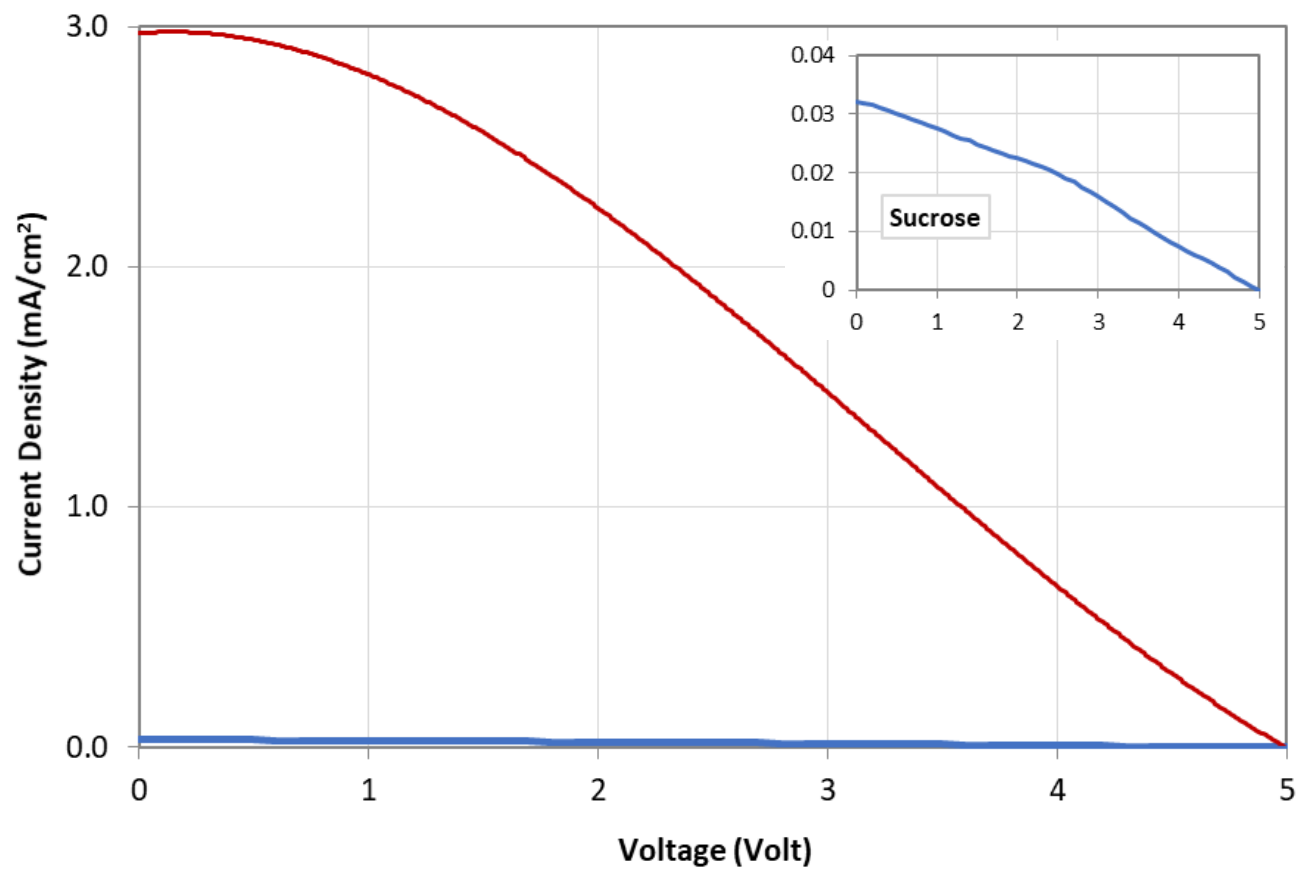

Figure $4 \mathrm{I}-\mathrm{V}$ curve of the DSSC device using carbon pyrolyzed from table sugar (Sample 3) as a counter electrode. Inset is detail of the I-V curve of the DSSC device using carbon pyrolyzed from sucrose (Sample 4) as a counter electrode.

Table 3 Power conversion efficiency (PCE) of the DSSC device with a counter electrode using platinum paste, carbon pyrolyzed from table sugar (Sample 3), and sucrose (Sample 4)

\begin{tabular}{lrrr}
\hline & Table Sugar & Sucrose & Platinum $^{*}$ \\
\hline $\mathrm{I}_{\text {oc }}(\mathrm{mA})$ & 3.006 & 0.032 & 10.280 \\
$\mathrm{~V}_{\text {oc }}($ volt $)$ & 5.000 & 5.000 & 4.800 \\
$\mathrm{I}_{\max }(\mathrm{mA})$ & 2.729 & 0.025 & 10.060 \\
$\mathrm{~V}_{\max }($ volt $)$ & 1.180 & 1.400 & 0.400 \\
$\mathrm{FF}$ & 0.214 & 0.213 & 0.082 \\
PCE \% & 3.239 & 0.041 & 4.024 \\
\hline
\end{tabular}

*Source: Sofyan et al., 2017

\section{CONCLUSION}

In this study, DSSC devices have been successfully fabricated using carbon pyrolyzed from the low-cost resources of table sugar and sucrose as counter electrodes. The results show that carbon with particles close to nanosize could be obtained using table sugar as a precursor by preheating to $300^{\circ} \mathrm{C}$ for 1 hour without the addition of a catalyst $(600-630 \mathrm{~nm})$, and using sucrose with the addition of a catalyst $(900 \mathrm{~nm})$. The DSSC device fabricated from the carbon produced using table sugar as a counter electrode exhibited a PCE of $3.239 \%$, whereas the carbon resulting from the use of sucrose as a counter electrode demonstrated a PCE of only $0.04 \%$. 


\section{ACKNOWLEDGEMENT}

The authors would like to express their gratitude for the funding from the Directorate of Research and Community Services (DRPM), Universitas Indonesia, through Hibah PITTA No. 823/UN2.R3.1/HKP. 05.00/2017.

\section{REFERENCES}

Al-Bahrani, M. R., Liu, L., Ahmad, W., Tao, J., Tu, F., Cheng, Z., Gao, Y., 2015. NiONF/MWCNT Nanocomposite Catalyst as a Counter Electrode for High Performance Dyesensitized Dolar Cells. Applied Surface Science, Volume 331, pp. 333-338

Chen, M., Shao, L-L., 2016. Review on the Recent Progress of Carbon Counter Electrodes for Dye-sensitized Solar Cells. Chemical Engineering Journal, Volume 304, pp. 629-645

Cullity, B.D., 1978. Elements of X-ray Diffraction $2^{\text {nd }} E d$., Massachusetts: Addison-Wesley Publishing Co. Inc.

Du, F., Yang, Q., Qin, T., Li, G., 2017. Morphology-controlled Growth of $\mathrm{NiCo}_{2} \mathrm{O}_{4}$ Ternary Oxides and their Applications in Dye-sensitized Solar Cells as Counter Electrodes. Solar Energy, Volume 146, pp. 125-130

Kumar, R., Nemala, S.S., Mallick, S., Bhargava, P., 2017. Synthesis and Characterization of Carbon-based Counter Electrode for Dye Sensitized Solar Cells (DSSCs) using Sugar Free as a Carbon Material. Solar Energy, Volume 144, pp. 215-220

Li, P., Wu, J., Lin, J., Huang, M., Huang, Y., Li, Q., 2008a. High-performance and Low Platinum Loading Pt/Carbon Black Counter Electrode for Dye-sensitized Solar Cells. Solar Energy, Volume 83, pp. 845-849

Li, Q., Wu, J., Tang, Q., Lan, Z., Li, P., Lin, J., Fan, L., 2008b. Application of Microporous Polyaniline Counter Electrode for Dye-sensitized Solar Cells. Electrochemistry Communications, Volume 10, pp. 1299-1302

O'Regan, B., Gratzel, M., 1991. A Low-cost, High-efficiency Solar Cell based on Dye-sensitized Colloidal $\mathrm{TiO}_{2}$ Films. Nature, Volume 353, pp. 737-740

Ramanakumar, A.V., Parent, M-É., Latreille, B., Siemiatycki, J., 2008. Risk of Lung Cancer Following Exposure to Carbon Black, Titanium Dioxide and Talc: Results from Two casecontrol Studies in Montreal. International Journal of Cancer, Volume 122, pp. 183-189

Sofyan, N., Ridhova, A., Yuwono, A.H., Udhiarto, A., 2017. Fabrication of Solar Cells with $\mathrm{TiO}_{2}$ Nanoparticles Sensitized using Natural Dye Extracted from Mangosteen Pericarps. International Journal of Technology, Volume 8(7), pp. 1229-1238

Wang, M., Zhao, Y., Yuan, S., Wang, Z., Ren, X., Zhang, M., Shi, L., Li, D., 2014. High ElectroCatalytic Counter Electrode based on Three-dimensional Conductive Grid for Dye-sensitized Solar Cell. Chemical Engineering Journal, Volume 255, pp. 424-430

Wu, C-S., Chang, T-W., Teng, T-W., Lee, Y-L., 2016. High Performance Carbon Black Counter Electrodes for Dye-sensitized Solar Cells. Energy, Volume 115, pp. 513-518

Zappielo, C.D., Nanicuacua, D.M., dos Santos, W.N.L., da Silva, D.L.F., Dall'Antônia, L.H., de Oliveira, F.M., Clausen, D.N., Tarley, C.R.T., 2016. Solid Phase Extraction to On-line Reconcentrate Trace Cadmium using Chemically Modified Nano-carbon Black with 3Mercaptopropyltrimethoxysilane. Journal of the Brazilian Chemical Society, Volume 27(10), pp. 1715-1726

Zhu, H., Li, X., Han, F., Dong, Z., Yuan, G., Ma, G., Westwood, A., He, K., 2015. The Effect of Pitch-based Carbon Fiber Microstructure and Composition on the Formation and Growth of SiC Whiskers via Reaction of Such Fibers with Silicon Sources. Carbon, Volume 99, pp. 174-185 